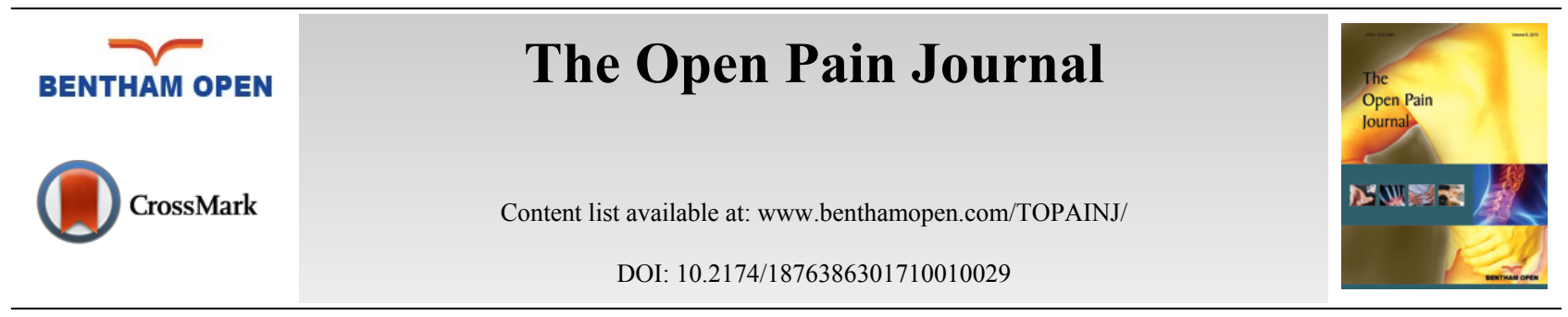

RESEARCH ARTICLE

\title{
Study of Evaluation of Symptoms of Juvenile Recurrent Parotitis Prior to and After Sialendoscopy
}

\author{
Bini Faizal $^{1, *}$, Sania Mariam Abraham ${ }^{1}$ and Krishnakumar $\mathrm{T}^{2}$ \\ ${ }^{I}$ Clinical Professor, Department of ENT, Amrita Institute of Medical Sciences, Amrita Vishwa Vidyapeedham, Kochi \\ ${ }^{2}$ Clinical Professor, Department of Head and Neck Surgery, Amrita Institute of Medical Sciences, Amrita Vishwa \\ Vidyapeedham, Kochi
}

Received: January 01, 2017

Revised: April 10, 2017

Accepted: April 13, 2017

\begin{abstract}
:
Background:

Juvenile recurrent parotitis(JRP) causes recurrent pain and swelling of one or both parotid glands in children. They are subjected to repeated courses of antibiotics and analgesics for this condition. Though self- limiting, some may progress to chronic parotitis which in some instances result in parotidectomy later on. But it does affect quality of life of the child with poor feeding during attacks and school absenteeism. Among various therapies, steroid lavage under endoscopic visualisation of the parotid salivary duct system has become popular after the advent of sialendoscopy. There are few studies comparing the response to conservative measures and salivary endoscopy.
\end{abstract}

\section{Objective:}

To evaluate the efficacy of sialendoscopy over medical management in JRP.

\section{Methodology:}

Twenty two patients of JRP between the age group 3 to 18 years were enrolled in this study. This retrospectively analysed the frequency of pain and parotid swelling after sialendoscopy. The results were compared to their pre intervention status when they were on medical management. Sialendoscopic management was offered only to those patients under medical treatment with symptoms of two or more attacks in 6 months.

\section{Results:}

Conservative measures as well as salivary endoscopy had good results, but latter fared better with regard to pain score and long remission. Majority were asymptomatic and the symptomatic patients experienced less pain with longer remission between attacks.

\section{Conclusion:}

Sialendoscopic visualisation and lavage seems to be a promising tool in the management of JRP. It appears that it contains the inflammatory process better and may prevent the progression to chronic parotitis.

Keywords: Juvenile recurrent parotitis, Sialendoscopy, Steroid lavage, Parotitis, Salivary endoscopy, Medical management of recurrent parotitis.

\section{INTRODUCTION}

Juvenile recurrent parotitis (JRP) is a non- obstructive and non- suppurative recurrent inflammation of the parotid gland in children. It has superseded mumps as the main cause for parotid enlargement in children after universal

* Address correspondence to this author at the Department of ENT, Amrita Institute of Medical Sciences, Amrita Vishwa Vidyapeedham, Kochi; Tel: +91 9446990937; E-mail: binifaizal@aims.amrita.edu 
vaccination [1]. Children usually present with facial pain, swelling of the parotid gland, tenderness and local and systemic rise of temperature. This non- specific and recurrent inflammation starts by one to two years of age, with varying remissions and exacerbations. Leerdam et al., described a biphasic presentation with the second peak after 10 years. The frequency of attacks determines the severity of JRP. The pathology is usually unilateral but bilateral swelling can also occur. The natural history of the disease and its recurrence and chronicity prompt clinician to evaluate for Sjogren syndrome, Mikulicz disease etc. In majority of cases, it tends to regress spontaneously after puberty. A small percentage of glands undergo progressive destruction and continue to adulthood as chronic parotitis [2, 3$]$.

The aetiology of the disease is known to be multi- factorial. These lead to decreased production and insufficient salivary outflow which favours ascending salivary gland infections from oral cavity. Causative factors include viral or bacterial infection, autoimmune disorders, allergy, hereditary factors and congenital ductal anomalies [3 - 5].Clinically a wide open parotid ostium is seen.

Pus is a rarity questioning the antibiotics administered routinely for the condition [6]. A B-mode ultrasound shows non- specific findings such as vacuoles which are hypoechoic denoting dilatation of intraglandular ducts with sialectasis. Histologically there is lymphocytic infiltration around intraductal cystic dialatation of peripheral ducts [4]. Ultrasonography may not show a stenosis. Other imaging modalities are rarely required [3, 7]. Sialendoscopy may be a superior diagnostic method though it is invasive $[8,9]$. In fact, JRP is one of the commonest indications for endoscopy in paediatric salivary disorders [10].

The treatment modalities range from conservative to invasive surgical procedures indicating the absence of a definitive one. Medical care includes analgesics, oral fluids, warmth, chewing gum and sialogogues. Cohen and colleagues recommended antibiotics during exacerbations since most of the expressed saliva cultured grew Streptococcus viridians and $H$. influenza $[8,11]$. Intractable cases were treated by intraglandular Botox injection, ductal ligation or in some instances parotidectomy [12 - 14]. In the recent years, there has been reports related to the management of JRP by sialendoscopy.

It is a safe and minimally invasive procedure performed through the primary duct to visualise ductal anomalies. The saline lavage performed to dilate the collapsed duct during the procedure washes away the debris and is found to be therapeutic too. Steroids in the lavage help by its anti-inflammatory effect. The typical endoscopic findings in JRP include duct devoid of vasculature with fibrosis of the ducts and mucinous discharge.

The duct size ranges from normal to varying stenosis depending on the severity of the disease. There is no consensus on the number of washes to be given though majority does single wash and further washes reserved for recurrences. However, subsequent washes show an improvement in vascularity in some cases with improvement in symptoms of pain and swelling $[9,15]$.

The aim of our study was to evaluate whether sialendoscopy and lavage really relieved the patients of their symptoms. There is a paucity of literature regarding this in our population.

\section{Aim of the Study}

Primary objective was to evaluate the efficacy of sialendoscopy over conservative methods in the treatment of juvenile recurrent parotitis.

The outcome variables studied were:

1. presence of pain or swelling after endoscopy;

2. number of flares after endoscopy;

3. period of remission after endoscopy.

\section{MATERIALS AND METHODS}

\section{Study Design}

It was a retrospective study conducted in a tertiary care centre. Twenty two patients between the age group 3 to 18 years diagnosed with symptoms of recurrent non suppurative parotid inflammation confirmed by ultrasonography were enrolled in the study. Conservative group included children with intractable symptoms managed medically during the flares. The condition was considered intractable if there are episodes of 2 or more severe attacks in 6 months requiring antibiotics resulting in school absenteeism or poor feeding. 
The sialendoscopy group included these very same patients with intractable disease who opted for intervention. Essentially, the study evaluated the pre and post intervention status of the same group of patients. Children diagnosed with Sjogren's disease, mumps, sialolithiasis or anaesthesia related contraindications were excluded from the study. The longest follow up was 3 years and the shortest 6 months.

\section{Methodology}

All children with suggestive history underwent ultrasonography and blood tests to screen for connective tissue disorders. Twenty two patients who underwent sialendoscopy for JRP formed the endoscopy group. Conservative group included the same group of patients in the endoscopy group prior to intervention.

Patients were asked to note down the recurrences in terms of pain, swelling, duration of remission and number of flares. Pain score was evaluated based on visual analogue scale (VAS) [16]. The endoscopy group underwent sialendoscopy and saline and steroid (Injection Hydrocortisone 100mg/ vial) lavage. Two washes were given at an interval of not less than 2 weeks. Their pain score was evaluated and then compared to their pre intervention score.

\section{Surgical Procedure}

All patients underwent sialendoscopy under general anaesthesia (GA). A single loading dose of injection Cefuroxime was given at the time of induction. Adequate exposure was achieved by keeping the mouth open using bite block and cheek retractors. Parotid papilla was identified opposite the upper second molar tooth. Dilatation of the papilla with salivary probes of increasing diameter enables the diagnostic sialendoscope to be passed through it. The system used was a semi rigid endoscopic device (reference 11576; Karl Storz Co., Tuttlingen, Germany). Duct visualization was achieved by pulsed rinsing through the endoscope with normal saline.

Diagnostic sialendoscopy allowed minimally invasive and complete exploration of the duct system accessible sometimes even up to tertiary or quaternary level as the case may be (Fig. 1A). Pale white duct mucosa without blood vessel which we call as "cadaveric" was typical of juvenile recurrent parotitis (Fig. 1B). Once confirmed, lavage of the parotid gland with $100 \mathrm{mg}$ of Hydrocortisone along with at least $60 \mathrm{ml}$ of normal saline was given. Gentamicin was added to the infusion if there was frank infection characterised by sialomucinous discharge. A second lavage was given after 2 weeks interval.

Usual hospital stay after procedure was 24 hours. The post intervention cheek swelling generally subsided by then. Only analgesics were given in the immediate postoperative period. During the postoperative visits patients were evaluated in terms of pain score based on visual analogue scale, number of flares and period of remission to assess the efficacy of treatment.VAS scores were categorised as those with score zero, five or less than 5 and more than 5 . Value of more than 5 denoted patients who needed antibiotics or analgesics.

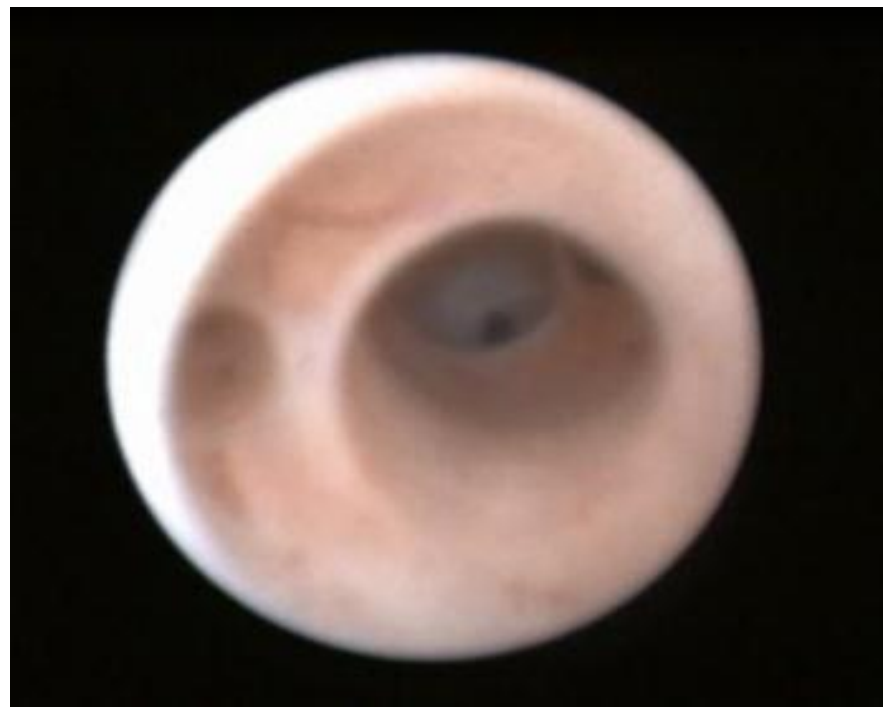

Fig. (1A). Normal salivary duct system on endoscopy. 


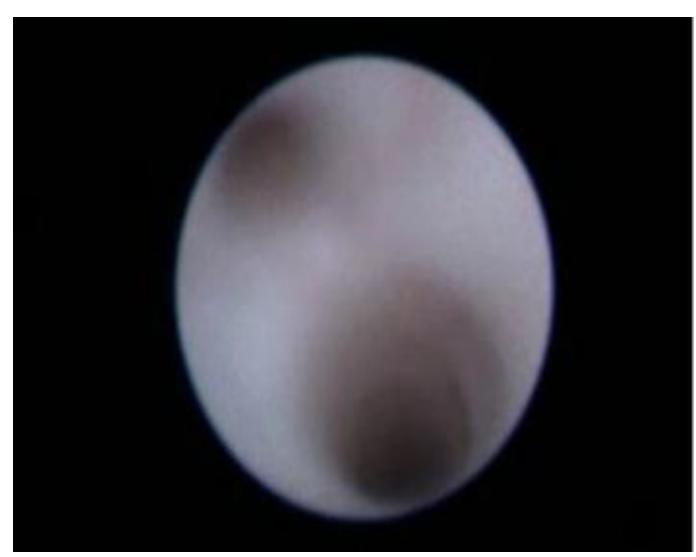

Fig. (1B). Loss of vascularity of the duct system in JRP.

\section{Ethical Clearance}

The study was cleared by our institutional review board. Authors attest that informed consent was taken from the guardians of the child and the work was performed maintaining all humane and ethical principles of research outlined in the Helsinki guidelines.

\section{Statistical Analysis}

The statistical analysis was conducted using Wilcoxon signed rank test.

\section{RESULTS}

Demographic data of the study population is given in Table $\mathbf{1}$.

Table 1. Pain scores and endoscopic findings of the study group. R-right side, L- left side, B/L- bilateral.

\begin{tabular}{|c|c|c|c|c|c|}
\hline No. & Age / Sex & VAS after medical management & VAS after sialendoscopy & Side & Findings \\
\hline 1 & $15 \mathrm{Y} / \mathrm{F}$ & 7 & 0 & $\mathrm{~B} / \mathrm{L}$ & Pale duct, stenosis \\
\hline 2 & $7 \mathrm{Y} / \mathrm{F}$ & 7 & 5 & $\mathrm{~B} / \mathrm{L}$ & Pale duct, stenosis \\
\hline 3 & $11 \mathrm{Y} / \mathrm{M}$ & 6 & 0 & $\mathrm{R}$ & Pale duct, stenosis \\
\hline 4 & $17 \mathrm{Y} / \mathrm{F}$ & 9 & 0 & $\mathrm{~B} / \mathrm{L}$ & Pale duct, stenosis \\
\hline 5 & $11 \mathrm{Y} / \mathrm{M}$ & 4 & 0 & $\mathrm{~B} / \mathrm{L}$ & Pale duct, stenosis \\
\hline 6 & $4 \mathrm{Y} / \mathrm{F}$ & 5 & 5 & $\mathrm{R}$ & Pale duct \\
\hline 7 & $7 \mathrm{Y} / \mathrm{M}$ & 7 & 0 & $\mathrm{~L}$ & Pale duct \\
\hline 8 & $6 \mathrm{Y} / \mathrm{M}$ & 2 & 4 & $\mathrm{R}$ & Pale duct \\
\hline 9 & $5 \mathrm{Y} / \mathrm{M}$ & 6 & 4 & $\mathrm{R}$ & Pale duct, stenosis \\
\hline 10 & $12 \mathrm{Y} / \mathrm{M}$ & 1 & 7 & $\mathrm{R}$ & Pale duct, stenosis \\
\hline 11 & $12 \mathrm{Y} / \mathrm{M}$ & 9 & 0 & $\mathrm{~B} / \mathrm{L}$ & Pale duct \\
\hline 12 & $18 \mathrm{Y} / \mathrm{F}$ & 6 & 0 & $\mathrm{~B} / \mathrm{L}$ & Pale duct, stenosis \\
\hline 13 & $4 \mathrm{Y} / \mathrm{F}$ & 5 & 0 & $\mathrm{~B} / \mathrm{L}$ & Pale duct, stenosis. \\
\hline 14 & $9 \mathrm{Y} / \mathrm{F}$ & 5 & 0 & $\mathrm{R}$ & Pale duct \\
\hline 15 & $11 \mathrm{Y} / \mathrm{M}$ & 7 & 0 & $\mathrm{~B} / \mathrm{L}$ & Pale duct, stenosis \\
\hline 16 & $12 \mathrm{Y} / \mathrm{M}$ & 8 & 1 & $\mathrm{~L}$ & Pale duct, stenosis \\
\hline 17 & $16 \mathrm{Y} / \mathrm{M}$ & 6 & 4 & $\mathrm{~L}$ & Pale duct, stenosis \\
\hline 18 & $6 \mathrm{Y} / \mathrm{M}$ & 7 & 2 & $\mathrm{~B} / \mathrm{L}$ & Pale duct, stenosis \\
\hline 19 & $15 \mathrm{Y} / \mathrm{M}$ & 7 & 0 & $\mathrm{R}$ & Pale duct, stenosis \\
\hline 20 & $5 \mathrm{Y} / \mathrm{F}$ & 9 & 2 & $\mathrm{R}$ & Pale duct, stenosis \\
\hline 21 & $16 \mathrm{Y} / \mathrm{M}$ & 4 & 0 & $\mathrm{~B} / \mathrm{L}$ & Pale duct, stenosis \\
\hline 22 & $16 \mathrm{Y} / \mathrm{M}$ & 7 & 4 & $\mathrm{~B} / \mathrm{L}$ & Pale duct \\
\hline
\end{tabular}

In the conservative group, $31.81 \%$ of patients had VAS score of 5 or less with rest having a score of more than 5 . More than half of the patients (54\%) had complete relief of symptoms following sialendoscopy, with a VAS of 0 . A VAS score of 5 or less was seen in $40.90 \%$. Score of more than 5 was seen only in one patient $(4.5 \%)$. The mean pain 
score of endoscopy group was 1.36 against a score of 6.45 for the conservative group. This was statistically significant with $\mathrm{p}$ value less than 0.001 . Comparison of pain score after medical management and sialendoscopy is shown in Table 1, (Fig. 2).

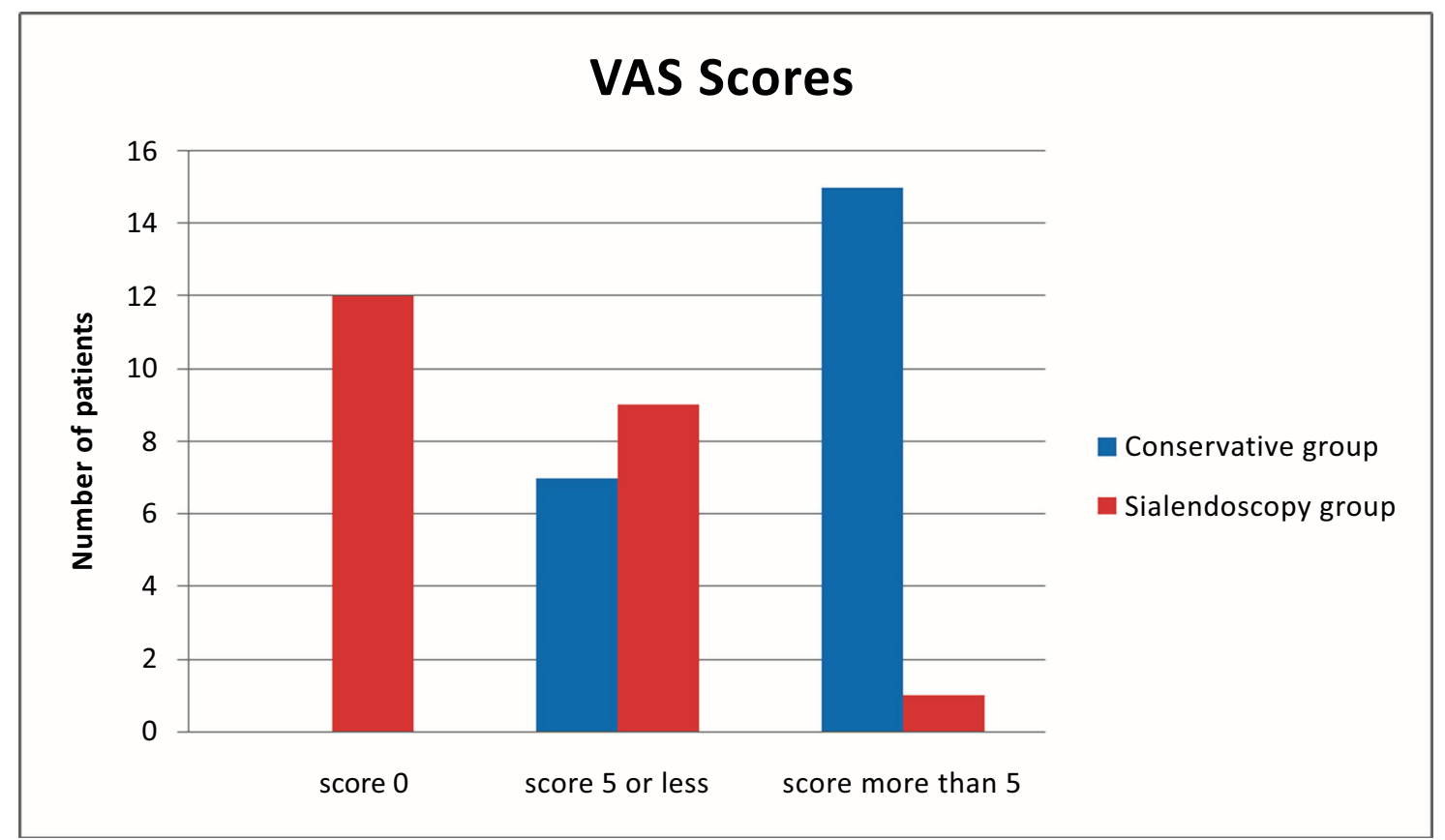

Fig. (2). Mean VAS score in the conservative and sialendoscopy groups.

In the medically managed group, $63.63 \%$ had a remission of 3 months or less. Six month remission was seen in $27.27 \%$ of patients. Two patients had remission up to one year. They were chosen for endoscopy since the subsequent flare was worse. In the sialendoscopy group, $22.72 \%$ had 3 month remissions. One year remissions were seen in $31.8 \%$. Forty five percent of patients had no flares at all (Fig. 3). This showed clear superiority of salivary endoscopy which was statistically significant $(\mathrm{p}<0.001)$.

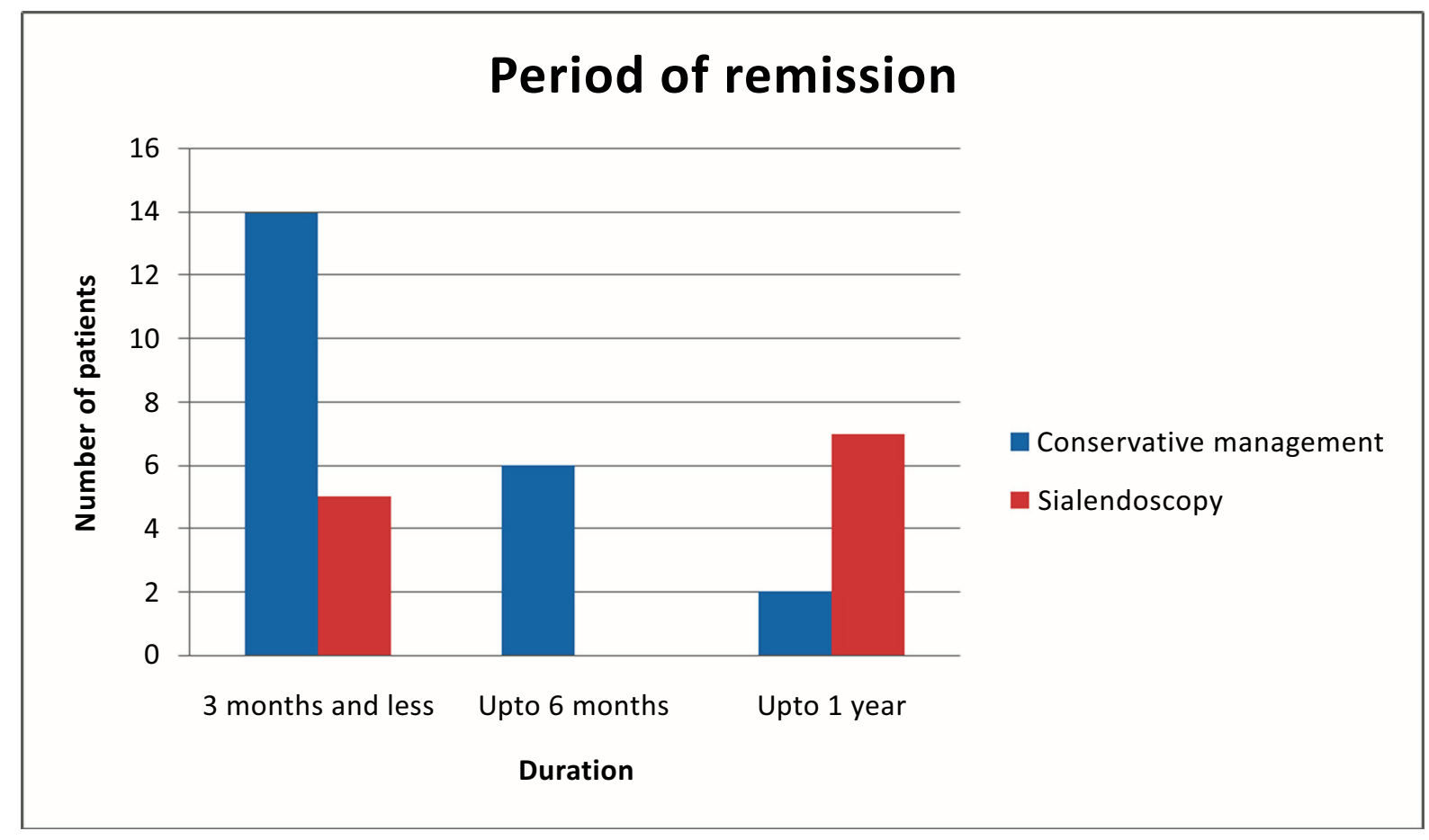

Fig. (3). Period of remission in the conservative and sialendoscopy groups. 
Regarding the number of flares, only 1 patient (4.54\%) treated medically had less than 2 flares. Seven patients $(31.8 \%)$ had 5 attacks and the remaining 14 patients $(63.63 \%)$ had more than 5 exacerbations. In the sialendoscopy group, 19 patients $(86.36 \%)$ had less than 2 attacks. Two patients $(9.09 \%)$ had 5 flares and only one patient (4.54\%) had more than 5 flares (Fig. 4). The comparison was statistically significant with a p value less than 0.001 .

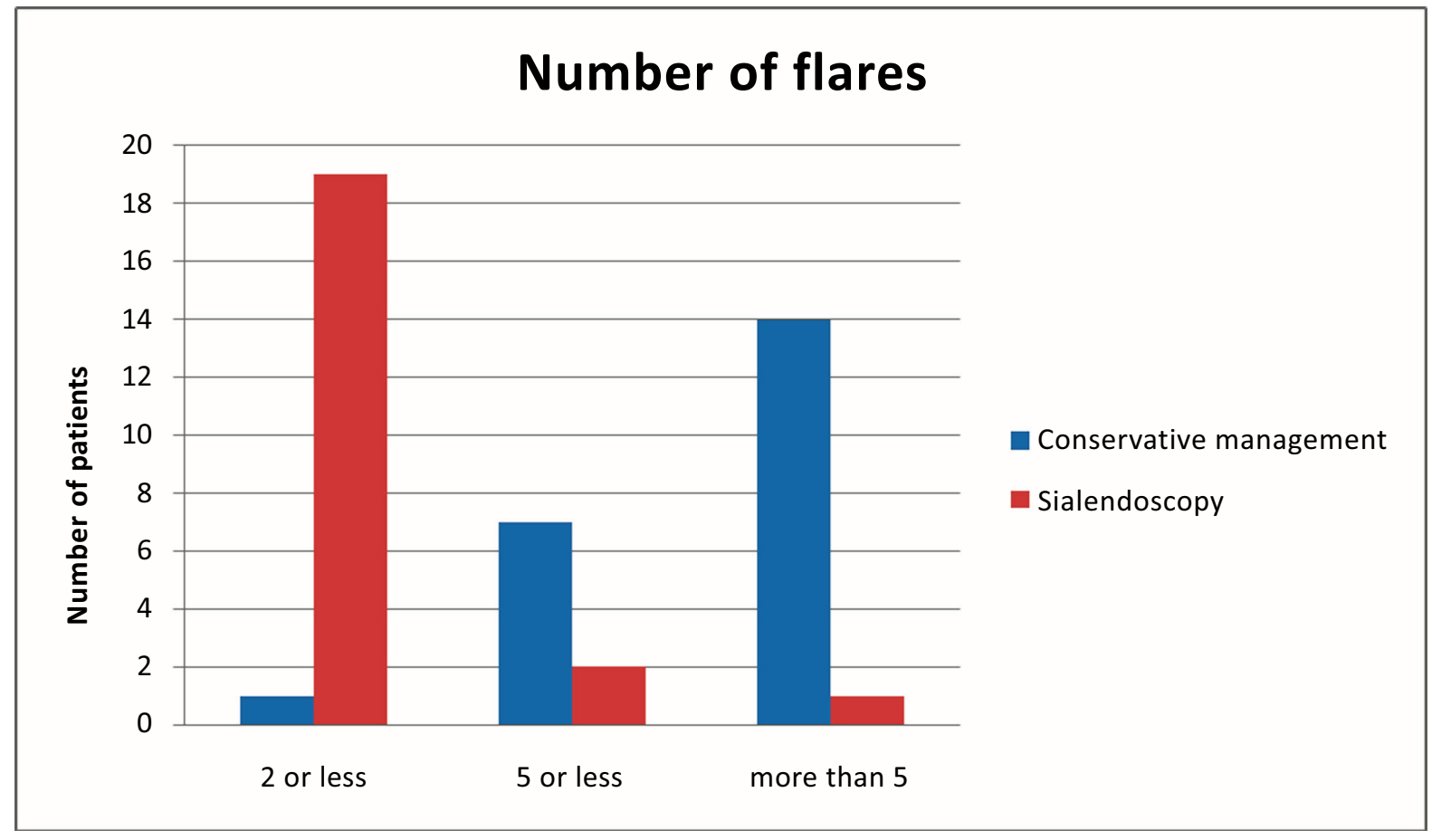

Fig. (4). Number of flares in the conservative and sialendoscopy groups.

\section{DISCUSSION}

Our study compared the efficacy of sialendoscopy over conservative management in the treatment of JRP. Both approaches have good results in terms of immediate response to reduction in pain and swelling. Long term analysis of the outcome measures like the incidence of pain and swelling, number of flares and period of remission showed a statistically significant superiority of endoscopy.

We personally feel sialendoscopy may be justified for patients with at least four flares in a year. The clinician should use his judgement as in two of our cases where endoscopy was performed for lesser number of attacks since they were pronounced. In other cases medical management looks more justified considering the cost of the procedure and general anaesthesia. In an analysis of 70 patients after lavage with steroids by Sachan et al., there was no recurrence in $93 \%$ of patients. The longest follow up period was 36 months [17]. In this largest series, endoscopic lavage was performed for 2 flares per year.

With patience and counselling some children may be treated medically since $92 \%$ treated medically ultimately become free of symptoms [18, 19]. Though paediatric sialendoscopy has been successfully reported under local anaesthesia, we continue to perform the same under general anaesthesia due to patient preference [20, 21]. Watkin and Hobsley observed the effects of antibiotic therapy and analgesia for acute flares. Over a follow-up period of 5 years, $64 \%$ improved medically. They opined that a self-limiting disease should be treated conservatively in the first instance $[19,22]$. Iro et al. suggested a therapeutic strategy based on the frequency of flares and the severity of symptoms. For infrequent flares and mild pain, conservative line was recommended.

With pronounced symptoms, sialendoscopy with cortisone irrigation after counselling parents was to be done. If there was recurrence with latter, parotidectomy was suggested with caution in choicest cases only [23]. In a recent study by him which is similar to ours, they found both methods to be equally efficacious [24]. But a child with troublesome symptoms does need interventional care with salivary lavage. Though cost factors and general anaesthesia may be sited as disadvantages of endoscopy, our study really shows that it does improve the quality of life of the child. 


\section{LIMITATION OF STUDY}

This study did not take into account the patients who improved by medical management alone and therefore did not come for further treatment. Because of ethical issues involved endoscopy being an interventional therapy was never offered as the first line of treatment. So the overlap of two arms was unavoidable. Whether steroid had the therapeutic edge over saline was not assessed. Radiological improvement in an asymptomatic patient after intervention was not assessed. Endoscopic and radiological improvements with lavage may be a subject of future research.

\section{CONCLUSION}

Steroid and saline lavage through sialendoscope improved the quality of life of the patients diagnosed with JRP. The long remission may prevent the glandular degradation and progression to chronic parotitis. We strongly recommend salivary endoscopy prior to other invasive procedures in intractable JRP.

\section{DISCLOSURE STATEMENT}

The authors have not received any funding from any external sources. There is no conflict of interests in this study.

\section{ETHICS APPROVAL AND CONSENT TO PARTICIPATE}

The study received Ethical approval by the scientific committee of Amrita Institute of Medical Sciences, , Kochi , India.

The approval number is Dissertation review/MD/MS/2015/40.

\section{HUMAN AND ANIMAL RIGHTS}

No animals were used in this research. All research procedures followed were in accordance with the ethical standards of the committee responsible for human experimentation (institutional and national), and with the Helsinki Declaration of 1975, as revised in 2008 (http://www.wma.net/en/20activities/10ethics/10helsinki/).

\section{CONSENT FOR PUBLICATION}

Not applicable.

\section{CONFLICT OF INTEREST}

The author confirms that this article content has no conflict of interest.

\section{ACKNOWLEDGEMENTS}

The authors acknowledge mr. Unnikrishnan, lecturer in statistics for his contributions.

\section{REFERENCES}

[1] Capaccio P, Sigismund PE, Luca N, Marchisio P, Pignataro L. Modern management of juvenile recurrent parotitis. J Laryngol Otol 2012; 126(12): 1254-60. [http://dx.doi.org/10.1017/S0022215112002319] [PMID: 23067864]

[2] Katz P, Hartl DM, Guerre A. Treatment of juvenile recurrent parotitis. Otolaryngol Clin North Am 2009; 42(6): 1087-91. [http://dx.doi.org/10.1016/j.otc.2009.09.002] [PMID: 19962009]

[3] Leerdam CM, Martin HC, Isaacs D. Recurrent parotitis of childhood. J Paediatr Child Health 2005; $41(12)$ : $631-4$. [http://dx.doi.org/10.1111/j.1440-1754.2005.00773.x] [PMID: 16398865]

[4] Ericson S, Zetterlund B, Ohman J. Recurrent parotitis and sialectasis in childhood. Clinical, radiologic, immunologic, bacteriologic, and histologic study. Ann Otol Rhinol Laryngol 1991; 100(7): 527-35. [http://dx.doi.org/10.1177/000348949110000702] [PMID: 2064262]

[5] Mandel L, Witek EL. Chronic parotitis: diagnosis and treatment. J Am Dent Assoc 2001; 132(12): $1707-11$. [http://dx.doi.org/10.14219/jada.archive.2001.0125] [PMID: 11780991]

[6] Brook I. Diagnosis and management of anaerobic infections of the head and neck. Ann Otol Rhinol Laryngol Suppl 1992; 155 : 9-15. [http://dx.doi.org/10.1177/00034894921010S103] [PMID: 1728904]

[7] Baurmash HD. Chronic recurrent parotitis: a closer look at its origin, diagnosis, and management. J Oral Maxillofac Surg 2004; 62(8): 1010-8. [http://dx.doi.org/10.1016/j.joms.2003.08.041] [PMID: 15278868] 
[8] Gadodia A, Seith A, Sharma R, Thakar A. MRI and MR sialography of juvenile recurrent parotitis. Pediatr Radiol 2010; 40(8): 1405-10. [http://dx.doi.org/10.1007/s00247-010-1639-1] [PMID: 20467735]

[9] Quenin S, Plouin-Gaudon I, Marchal F, Froehlich P, Disant F, Faure F. Juvenile recurrent parotitis: sialendoscopic approach. Arch Otolaryngol Head Neck Surg 2008; 134(7): 715-9.

[http://dx.doi.org/10.1001/archotol.134.7.715] [PMID: 18645120]

[10] Nahlieli O, Shacham R, Shlesinger M, Eliav E. Juvenile recurrent parotitis: a new method of diagnosis and treatment. Pediatrics 2004; 114(1): 9-12. [http://dx.doi.org/10.1542/peds.114.1.9] [PMID: 15231901]

[11] Martins-Carvalho C, Plouin-Gaudon I, Quenin S, et al. Pediatric sialendoscopy: a 5-year experience at a single institution. Arch Otolaryngol Head Neck Surg 2010; 136(1): 33-6. [http://dx.doi.org/10.1001/archoto.2009.184] [PMID: 20083775]

[12] Cohen HA, Gross S, Nussinovitch M, Frydman M, Varsano I. Recurrent parotitis. Arch Dis Child 1992; 67(8): 1036-7. [http://dx.doi.org/10.1136/adc.67.8.1036] [PMID: 1303637]

[13] Fuster Torres MA, Berini Aytés L, Gay Escoda C. Salivary gland application of botulinum toxin for the treatment of sialorrhea. Med Oral Patol Oral Cir Bucal 2007; 12(7): E511-7. [PMID: 17978775]

[14] Moody AB, Avery CM, Walsh S, Sneddon K, Langdon JD. Surgical management of chronic parotid disease. Br J Oral Maxillofac Surg 2000; 38(6): $620-2$ [http://dx.doi.org/10.1054/bjom.2000.0478] [PMID: 11092780]

[15] Daud AS, Pahor AL. Tympanic neurectomy in the management of parotid sialectasis. J Laryngol Otol 1995; 109(12): 1155-8. [http://dx.doi.org/10.1017/S0022215100132311] [PMID: 8551145]

[16] Marchal F, Becker M, Dulguerov P, Lehmann W. Interventional sialendoscopy. Laryngoscope 2000; 110(2 Pt 1): 318-20. [http://dx.doi.org/10.1097/00005537-200002010-00026] [PMID: 10680937]

[17] Emergency Care Acute Pain Management Manual National Health and Medical Research Council. Canberra 2011. Available at: http://www.nhmrc.gov.av/guidelines-publications(cp135)

[18] Shacham R, Droma EB, London D, Bar T, Nahlieli O. Long-term experience with endoscopic diagnosis and treatment of juvenile recurrent parotitis. J Oral Maxillofac Surg 2009; 67(1): 162-7. [http://dx.doi.org/10.1016/j.joms.2008.09.027] [PMID: 19070763]

[19] Watkin GT, Hobsley M. Natural history of patients with recurrent parotitis and punctate sialectasis. Br J Surg 1986; 73(9): 745-8. [http://dx.doi.org/10.1002/bjs.1800730922] [PMID: 3756441]

[20] Konstantinidis I, Chatziavramidis A, Tsakiropoulou E, Malliari H, Constantinidis J. Pediatric sialendoscopy under local anesthesia: limitations and potentials $2011 ; 75(2): 245-9$. [http://dx.doi.org/10.1016/j.ijporl.2010.11.009]

[21] Papadopoulou-Alataki E, Chatziavramidis A, Vampertzi O, Alataki S, Konstantinidis I. Evaluation and management of juvenile recurrent parotitis in children from northern Greece. Hippokratia 2015; 19(4): 356-9. [PMID: 27688702]

[22] Geterud A, Lindvall AM, Nylén O. Follow-up study of recurrent parotitis in children. Ann Otol Rhinol Laryngol 1988; $97(4$ Pt 1): $341-6$. [http://dx.doi.org/10.1177/000348948809700403] [PMID: 3408108]

[23] Iro H, Zenk J. Salivary gland diseases in children. GMS Curr Top Otorhinolaryngol Head Neck Surg 2014; 13 [PMID: 25587366]

[24] Schneider H, Koch M, Künzel J, et al. Juvenile recurrent parotitis: a retrospective comparison of sialendoscopy versus conservative therapy. Laryngoscope 2014; 124(2): 451-5.

[http://dx.doi.org/10.1002/lary.24291] [PMID: 23818258]

(C) 2017 Faizal et al.

This is an open access article distributed under the terms of the Creative Commons Attribution 4.0 International Public License (CC-BY 4.0), a copy of which is available at: (https:/creativecommons.org/licenses/by/4.0/legalcode). This license permits unrestricted use, distribution, and reproduction in any medium, provided the original author and source are credited. 